\title{
Medical Research by the Medical Colleges in India
}

\author{
Kanjaksha Ghosh ${ }^{1}$, Kinjalka Ghosh ${ }^{2}$ \\ Surat Raktadan Kendra \& Research Centre, Surat, Gujrat ${ }^{1}$, \\ Deptt. of Clinical Biochemistry, Tata Memorial Hospital, Mumbai².
}

\begin{abstract}
Background: Research conducted in medical colleges in India is often considered to be of poor quality. The study was done to assess the cause for such occurrence.

Materials and Methods: Papers published in indexed journals between 1985 to 2017 were reviewed and the data was synthesized.

Results: Poor infrastructure, heavy patient load, restricted number of faculties who had limited exposure to research methodologies, private practice, lack of incentive to do good quality research, poor mentoring, lack of research tradition, research fund, ancillary infrastructures, and copy cat research were found to be some of the reasons.

Discussions and Solutions: Teachers education, provision of better infrastructure and funding, short term fellowships at both undergraduate and postgraduate levels, proper assessment for promotion of teachers, training in research methodology, multicentric research, R \& D research bases in medical colleges, looking for solutions for day-to-day challenges through operational and translational mode are some of the solutions. Training from undergraduate levels on elements of research needed to be encouraged.
\end{abstract}

Keywords: UG medical student, training, research methodology challenges, teachers education.

\section{Situational Analysis}

There are more than 450 medical colleges in India churning out around 60000 medical graduates per year. Out of these, $50 \%$, i.e. 30,000 graduates do various types of postgraduation or superspecialisation. This does not include parallel DNB examination at the specialization / superspecialisation level. Hence it may be assumed that as per Medical Council of India (MCI) requirement these 30,000 postgraduates / superspecialists (MD/ MS/ DM /MCh) are submitting so many dissertations every year. How good are these dissertations. One of the ways to assess the quality of these theses is to ask the authors, what they feel about it. Our experience is that students hardly feel any attachment to their theses and less than $10 \%$ of such dissertations are eventually published as full papers in any of the national indexed journals. There are a handful of medical colleges where sufficient interest is shown by the faculty in mentoring the postgraduates and reasonably good publications come out of from a few students from these handful of medical colleges.

Biomedical research of some quality is conducted by independent research

Correspondence : Prof. Kanjaksha Ghosh, Director, Surat Raktadan Kendra \& Research centre, 1st Fl. Udhna Khatodara Urban Health Centre, Beside: Chosath Joganio Mata Mandir, Udhna Magdalla Road, Surat-395002, Gujrat. Email :kanjakshaghosh@gmail.com. 
organizations or their Institutes like Indian Council of Medical Research (ICMR), Council of Scientific and Industrial Research (CSIR), Department of Biotechnology (DBT), Indian Institute of Sciences (IISc), etc. to name a few. Even from these organizations and Institutes, real collaborations with medical colleges are few and far between. Hence many of the important day-to-day challenges which the doctors in medical colleges and other hospitals are facing do not find an echo in the nature of research done by the august organizations leading to a disconnect between the requirement and the product. Since 1990s several scathing criticisms on the nature of research in medical colleges in India has been published (1-5). In those articles not only poor quality of research but academic dishonesty, poor output of research paper were also highlighted. A review of that time (1) analyzing 128 medical colleges commented only top 6 college published $56 \%$ of total research papers. We would like to see what could be possible reasons for such an affair and whether something can be done about it.

\section{Mediocrity Rules the Roost}

To mentor a student for research we need good mentors. However, at the medical college level majority of the teachers are not well versed with science and art of medical research. Methodology, how to find out the problem, how to devise a study, analyzing the ethical component and address them and finally conducting the study are the important components of medical research. Like in many areas of education medical education in India in many ways are incomplete. Churning out large number of doctors with bare minimum training and finally inducting them as teachers in those medical colleges are a few reasons for such mediocrity in research.

\section{Lack of Incentives}

There are no incentives for good research work. Promotions require that faculties at different levels when considered should have at least one, two or few publications. But MCI does not specify what sort of publications is to be counted, at what level of authorship? How many students are mentored, what these students eventually produced? What other engagement should also be considered as research-related engagement, i.e. peer reviewer of good journals, members of project review committee constituted by funding agencies, assessor of $\mathrm{PhD}$ level research from good institutions, engagement in community-based research activity etc. In fact, faculties across the country in medical colleges are regularly promoted without a track record of mentoring or doing research. What to talk about faculty in medical colleges, private and government medical colleges are running with contributions from ghost faculty who comes during MCI inspection and then is heard no more.

In case of government medical colleges authorities assemble faculty from other colleges or temporarily transfers faculty from other colleges to tide over the crisis of MCI inspection for adequate infrastructure and faculty. Modern era of pay and publish your research also destroyed whatever little credibility of medical college faculties had by publishing something in local medical journals and using them for their promotion.

\section{Private Practice is the be All and End All Motto}

How can a medical faculty in a medical college give time to his students for training and research when he is always looking at his watch when to leave the premises for private practice. It is difficult to blame the faculty entirely for such a state of affairs because they are not always paid well, they don't have other amenities which a good medical college should have provided and even many families looks at the doctor for earning adequate money for the extended family. Private medical colleges are not cheap, many teachers who came from such colleges have a huge debt burden to be paid for by their earning. Society also now-a-days do not look with respect 
to a doctor who is dedicated to his college and do not earn extra dime through private practice.

One is not surprised that now-a-days to see private clinics running upto midnight, how then this doctor will come to the medical college next day morning, see patients, teach both undergraduate and postgraduate students, mentor his postgraduates for research and finally do his own research? In fact Reddy et al (2) blames private practice as the major cause of poor research performance by medical colleges in India.

\section{Huge Patient Load}

Every hospital particularly Government medical colleges and some very good private medical colleges have extremely high patient load and it is often physically impossible to give attention to all the patients that attend these centres. The faculty and junior doctors in our country day in and day out face such overwhelming crowd of distressed humanity. Hardly they can spend more than a minute or two with each patients. Though this improves their clinical skills (do they? ) this does not produce an ideal environment for patient-based research, which medical colleges are supposed to do. Hence crowd management rather than proper patient management takes the front seat and research can be seen nowhere. We often speak of our patient load, a golden opportunity to do good quality clinical research but their humongous number itself prevents such an enterprise to take root.

\section{Extremely Poor Infrastructure in Medical Colleges}

Most of the medical colleges in India has extremely poor infrastructure. Many of the modern investigations which are required for day-to-day patient care often needs to be outsourced. This can easily be seen when one moves outside the medical college campus and sees proliferation of private laboratories to cater for the patients. Many of these laboratories are now famous laboratory chains across the length and breadth of the country. While patient care somehow can be managed with this approach training and research in medical colleges suffer. Most of the medical colleges also do not employ medical statistician and the case files in many colleges are poorly written, cursory and incomplete so also the hospital record section.

Many hospital-based research, particularly retrospective research is dependent on good quality medical records and its proper archiving, which is sadly lacking in most of the medical institutions in India. Experimental studies which requires laboratory animal facility has also vanished from majority of the medical colleges in the country, or it was never constructed in many newer medical colleges. Medical colleges also have no special funds to carry out research. It is extremely sad that from each of these medical colleges, each year so many doctors are coming out, many of them become successful medical practitioners, earn lots of money but donate next to nothing to their alma mater. This is in contrast to IITs in India. In fact personal donations should have produced huge corpus in each of these colleges to drive research. For example if out of the 60,000 medical graduates produced by the country even if $10 \%$ of them becomes successful medical practitioners then we are talking of 6000 successful doctors each year and they donate only once in their life a sum of 100,000 rupees then $6,000 \times 100,000$, i.e. 60 crore rupees of personal donation should flow each year to these medical colleges and in the span of 30 years we could have 1800 crore rupees of personal donation meaning thereby a corpus of at least 4-6 crore rupees to each of the medical college in India to drive research.

\section{Copy Cat Research}

Many dissertations and research projects written are basically copycat research. While there is no harm if copy cat research improves our health care infrastructure and our students understanding how good research can be 
conducted. But 100\% copycat researches eventually do not bring any original thinking, meet the local medical needs or successfully face the research challenges in the country. This has been highlighted in detail by Arunachalam (6).

\section{Lack of Collaborative Research Activities}

Now-a-days many good research emanates from joint, multicentric research. It seems in our country we are incapable of doing collaborative research except few examples, whereas in international arena often hundreds of medical centres take part with a common research goal. Such kind of research easily attracts attention because of its sheer size, brings about statistically robust facts. It can be seen the mega trials which brought aspirin in the secondary prevention of ischemic heart diseases would have been possible without several of those mega trials. Those trials are not difficult but time consuming to the trialists.

\section{Inadequate Follow-up}

This is one of the biggest problem which conspires against conducting good quality research in our country. Without blaming patients, doctors, institutions and the facilities it can be said our patients do not understand the need to come back for follow-up to the doctor to say that I am well or I did not get well with whatever was prescribed. This lack of follow-up not only hampers research but more than that the doctors does not come to know that whatever he prescribed worked or not, hence he loses one of the most important avenues of continuous medical education. Probably patient feels I am alright with his medicine hence why should I go back to him or his medicine did no good what is the point in going back to him. In both ways patient also becomes a loser, for diseases like tuberculosis patient feels better within 2-3 weeks of therapy and stops medicine, does not go back to his doctor. Had he done that doctor would have told him to continue the medicine. This results in emergence of multidrug- and extensively drug-resistant tuberculosis
(M/XDR-TB), relapse in the patient, more costly and eventually less successful intervention. Part of this non follow-up could be financial but partly this is in our national persona.

\section{Funding Agencies}

In India, several government funding agencies fund medical research. These agencies are ICMR, DBT, Department of Science and Technology (DST), CSIR, Board of Research in Nuclear Sciences (BRNS), etc. Unfortunately many private industries which could have put up some fund for research are nowhere to be seen. If one concentrates and see the funding pattern from these organizations, it will be apparent that 15-20 institutes/medical colleges in this country corner $70 \%$ of the funds available for adhoc projects. The reasons for this are many and one of them is of course the few successful institutions write better quality projects but other reasons will not be very palatable to the funding agencies. Recently each state has developed their modest research funding patterns and ICMR has given substantial funds to almost 100 medical colleges in the country for improving research atmosphere in those colleges. ICMR/ DBT is also individually funding students at undergraduate / postgraduate levels to do project or thesis work. However, number of such grants are less and amount is also insufficient.

Recently three national science academies in the country together are encouraging faculties from different colleges to spend some time as summer trainees to some of the centres of excellence to develop some ideas related to developing research protocols in their home institutions. All research funding organizations are also spending $10 \%$ of their budget to stimulate research activities and develop research infrastructures in North Eastern states of India.

However, all these measures are recent and we have to see whether these interventions make any difference in research activities in these institutions in future. 


\section{R\&D of Pharmaceutical Industries and its Co-ordination with Nearby Medical Colleges}

India has one of the biggest pharmaceutical industries in the world, barring few, yet R\&D, in these industries are meager. If majority of these pharmaceutical industries could open a collaborative $R \& D$ centre in various medical colleges it will be a win-win situation. In olden days, Burroughs Wellcome used to have such R\&D centres in RG Kar Medical College, Kolkata and in CMC, Vellore. This kind of centres depending on the particular company's strength can generate interest in different areas of biomedical research in the country. Department of Health Research (DHR), Government of India is supposed to see that this kind of collaborations happen in a grand scale. In addition we have a tremendous traditional medicine heritage at the level of medical colleges Ayurveda, Yoga, Unani, Siddha and Homeopathy (AYUSH)/DHR/ICMR/Central Council for Research in Homeopathy $(\mathrm{CCRH})$ can harness collaborative research to bring out the best and popularize the use of such medical approaches for common ailments. As an example, studies in modern institutions funded by ICMR has shown Ksharasutra method of treatment for anal fistula is better than classical surgical technique. But have we popularized its use? The answer is no. As a result of this, current generation of surgeons may not have even heard the name Ksharasutra.

This kind of collaboration to a large extent also will bring necessary funds for research in a medical college. This will also end total apathy due to ignorance of modern medical doctors to the gems of ancient Indian knowledge in medicine.

\section{Hindrances in Randomised Control Trials}

Randomised control trials (RCTs) may not bring basic research in medical colleges but being a part of it teaches faculty of a medical college the rigor of doing a good clinical research. This kind of research brings good amount of money to the organization and brings national and international fame to the medical colleges. There are rules and regulations to make such trials safe (as much as it can be) to the volunteer patients for this trial. However, the rules and regulations for giving this trial in this country has become so tight and getting permission to do the trial are so time consuming that the very idea to conduct an RCTs in India immediately brings negative feeling. While we must agree to tighten all the norms for the purpose of safety, yet we should not tighten it to such a degree that no worthwhile trial can be stopped.

\section{Needs to Revamp its Curricula/Syllabus for Medical Education}

In modern era there is a need to revamp medical syllabus. Lots of clinical research done in India is not studied by our postgraduates as they mainly study international books. Modern research needs basic scientists in addition to doctors. AIIMS has research scientists post at various departments. Prof. Karmarkar without being a medico became Professor of Medicine in AIIMS. MCI must at least create adjunct faculty/adjunct professor post to improve research in medical colleges. These adjunct professors could be from a general college, engineering college, and research institutions. There should be stricter norms for considering a paper for promotion. Other elements of research activity also needs to be considered.

\section{Research is not Divorced from day-to-day Practice}

One of the major problems in modern medical teaching in India is that research has not been any priority and it has been made to appear that research is really divorced from our day-today medical practice, which is not. All our medical teaching including bedside teaching, particularly needs to focus on that.

Basically such type of orientation should start from undergraduate levels. Several 
examples can be given, e.g. if you take 10 patients of myocardial infarction and look into details their clinical presentations, all ten will be different, we may not know all the reasons but a student should have the inquisitiveness to enquire why ten fellows are presenting differently, i.e. some with epigastric discomfort, some with profuse diaphoresis, some with pain in the hand and some with pain in the jaw, etc.

\section{Quality of Teaching and Teachers in Medical Colleges}

Good quality and number of researches can come out of the medical colleges only if the college has good and proper teaching credential. Poor teaching and lack of adequate faculty in many medical colleges has been pointed out by early workers (7-9). Some of them also have pointed this out in their inimitable writing style (10). We present many research papers in our different annual conferences and very few of them are eventually published. Quite often these abstracts are prepared by postgraduates but lacking in final push it does not see the light of the day in the form of a valid publication (11). Though postgraduate students are supposed to do research in the form of dissertations (12), they often not properly mentored by their guide. There could be different reasons for such a lacunae. Moreover teachers of medical colleges who are usually the guide hardly have any time for mentoring. Many of them are not also qualified to do so because they lack education and training in that area. Some Institutes do have research methodology course which must be undertaken by $\mathrm{PG}$ students but this is not universal. Hence the PG students who are the future teachers of the country grow up in cut and paste mode without learning any elementary principles of modern medical research.

\section{Examples of Medical Institutions doing Good Quality Research}

Solutions to improve research capabilities in the medical colleges in India can come from taking examples from those medical colleges which are already known to be in the forefront of medical research in the country. For example institutions like PGIMER, Chandigarh, AIIMS, New Delhi, SGPGI, Lucknow are known to be regularly producing good quality research article. These government medical colleges are reasonably well funded. The faculties from these institutes are well represented as experts and reviewers of most of the Government funding agencies and these institutes discourage private practice, however the salary of the doctors are some of the best in the country and they all can take the advantage of institutes accommodation. The selection procedure for the faculty is tough and there are no regular avenues of promotion as well as chances for them to go abroad for a period of two years to get a fruitful academic experience besides of course and earn far from ideal extra money. In addition these institutes have developed programmes with some of the best western Institutes to carry on high quality research. In some of these organizations a strong assistance from non-medical scientists cadre exist and unusual departments like department of experimental medicine in PGIMER, Chandigarh cooperating with other clinical departments for doing research. We also have medical colleges like KEM Hospital, Mumbai where reasonably good quality research goes on even though the faculty members practice outside and they do not have many of the facilities of the above mentioned colleges, hence in many ways this institute resembles most of the other medical colleges in India. Moreover being in the hub of financial capital of India, there are lots of reason for the faculties to get distracted from research. This institute also has a long research culture in having their own research society and there are many ICMR research centres and other research institutions around this medical college which definitely helps KEM Hospital in developing many collaborative research work. Then there are premier medical college-cum-research organization like CMC Vellore where both national and international collaboration and research programme brings money, projects and good name to the institute and here also no private practice is allowed. 


\section{Solutions}

So how we can make medical college faculties to get engaged in good quality research programmes? First the faculty should feel an urge to do research and this starts from when a future faculty as an MD student writes his / her dissertation. If his boss is exacting he can learn the elements of medical research from him. Now-a-days research methodology course has been started for postgraduate medical students, this could be made universal and interesting. Faculties should be rewarded for publishing good quality research papers or bringing competitively funded project to the college or when they are selected in peer review committees of national or international funding agencies. If any nearby good non-medical research institution is there, the faculty should try to tie up with them to produce good project. ICMR in an effort to start good research in medical colleges have already started funding small ICMR research units across the country with instrument and manpower support. The administrators of state medical colleges must understand that modern medicine is progressing in such a way that many departments in a medical college are in need of non-medical scientists, hence a cadre of non-medical biological scientists needs to be created for different departments of medical colleges to suit the needs of individual departments. Several authors suggested a number of solutions to address this problem, i.e. mentoring, researchoriented medical education, short-term student funding at undergraduate and postgraduate levels, workshops, hand-holding by good research organizations, improving the quality of the faculty, reducing the patient load and teaching some of the Indian medical research finding in the curricula (13-17). In the MBBS curricula, the only subject where how to do medical research is taught in a very elementary way is Preventive and Social Medicine (Community Medicine). However, MBBS students pay little interest to this subject. This subject should be made more interesting. In some universities, an additional BSc (Hons) degree is given if a candidate takes one year extra to do some quality research in any of the subjects being taught in MBBS level. This could be difficult in this country but similar programme which are student friendly could be initiated.

Now that the study of medical scientometry (18) is with us and many of the medical journals are internationally indexed as well as we have our own indexing agencies; it is unlikely that like previous decades our research work will be lost to the international community, only we have to conduct good quality, locallyrelevant research for our country.

\section{Conflict of Interest}

None.

\section{Acknowledgement}

None.

\section{References}

1. Tullu MS, Karande S (2016). Quality research in Indian medical colleges and teaching institutions: the need of the hour. JPostgrad Med 62:213-215.

2. Reddy KS, Sahni P, Pande G K, Nunday S (1991). Research in Indian medical institutes. Nat Med J Ind 4:90-92.

3. Gitanjali B (2004). Academic dishonesty in Indian medical colleges. $J$ Postgrad Med 50:281-284.

4. Bagcchi S (2016). Nearly six in 10 medical colleges in India did not publish any research in past 10 years. $\mathrm{Br}$ Med $J$ 353:i2352.

5. Pandya S (1990). Why is the output of medical research from India low? $\mathrm{Br}$ Med J301:333. 
6. Arunachalam S (1997). How relevant is medical research done in India? A study based on Medline. Curr Sci 72: 912-922.

7. Kaushik M, Roy A, Bang AA, Mahal A (2008). Quality of medical training and emigration of physicians from India. $B M C$ Health ServRes 8:279.

8. Deswal BS, Singhal VK (2016). Problems of medical education in India. Int J Comm Med Public Health 3: 1905-1909.

9. Ananthakrishnan N, Arora NK, Chandy G, et al (2012). Is there need for a transformational change to overcome the current problems with postgraduate medical education in India? Natl Med $J$ India 25:101-108.

10. Anand AC (2009). Medical education in India: moments of pensive introspection. Trop Gastroenterol 30: 54-58.

11. Mittal H, Gupta P (2011). Fate of award winning papers at annual conference of Indian Academy of Pediatrics: a 13 years experience. Indian Pediatr 48: 818-819.

12. Bhawalkar J, Jadhav S, Banerjee A, Kulkarni P, Bayan P, Shachi A (2014). Research trends in post-graduate medical students, Pune. Ann Med Health Sci Res 4: 355-360.
13. Deo MG (2013). Research-oriented medical education for graduate medical students. Natl Med J India 26(3):169-173.

14. Sharath BN, Shilpashree MK, Menezes RG, Bansal AK (2015). Tuberculosis research in Indian medical colleges: has it taken a back seat? Public Health Action 5: 202.

15. Dhulkhed VK, Kurdi MS, Dhulkhed PV, Ramaswamy AH (2016). Faculty promotions in medical institutions in India: can we improve the criteria? Indian JAnaesth 60: 796-800.

16. Deo MG (2009). Need for research oriented medical education in India. Indian J Med Res 130:105-107.

17. Deo MG (2008). Undergraduate medical students' research in India. J Postgrad Med 54:176-179.

18. Gupta BM, Bala A(2011). A scientometric analysis of Indian research output in medicine during 1999-2008. J Nat Sci Biol Med 2: 87-100. 